\title{
AUTOMATED SYSTEM FOR CONTINUOUS MICROALGAE CULTIVATION IN PHOTOBIOREACTORS
}

\author{
D. A. L. D'Agostin', \\ G. M. Domene ${ }^{a}$, \\ A. S. Oliveira ${ }^{a}$, \\ M. J. C. Bonfim ${ }^{\text {, }}$ \\ and A. B. Mariano ${ }^{\mathrm{a}, \mathrm{b}}$ \\ ABSTRACT \\ The objective of this work was to design a automate system for microalgae \\ cultivation on a continuous modes in laboratory scale and allow its remote \\ monitoring and control. For this, a sensor were developed is able to measure \\ biomass concentration. The concentration sensor used the principle of light \\ scattering, that is, by measuring the turbidity of the culture medium by the \\ use of a set of phototransistor and green led. It presented an mean absolute \\ percentage error of $8.46 \%$ during the experiment. $\mathrm{A} \mathrm{pH}$, temperature and \\ light sensor were also installed. The control of all the sensors was \\ accomplished by means of an microcontroller. For remote control and \\ monitoring of the controller, a database was designed and implemented on a \\ Raspberry Pi connected to the network. The graphics and data collected are \\ available on an HTML page that allows changes in the control mode of the \\ photobioreactor, for example by changing the dilution rates. The controller \\ was able to operate the photobioreactor in batch mode, as well as to \\ maintain the culture operating in continuous regime. The continuous \\ production of microalgae biomass in a continuous regime showed \\ productivity $74.5 \%$ higher than the traditional batch process and $28.2 \%$ \\ higher than semicontinuous cultivation. \\ CP. 19011, Curitiba, Paraná, Brasil. \\ andrebmariano@gmail.com \\ Received: February 17, 2017 \\ Revised: November 05, 2017 \\ Accepted: December 08, 2017 \\ Keywords: biofuels, microalgae, continuous cultivation, automation
}

\section{NOMENCLATURE \\ $\mathrm{X}$ biomass concentration, $\mathrm{mg} / \mathrm{L}$ \\ $\mathrm{S}$ substrate concentration, $\mathrm{mg} / \mathrm{L}$ \\ $\mathrm{S}_{\mathrm{f}} \quad$ feed substrate concentration, $\mathrm{mg} / \mathrm{L}$ \\ $\mathrm{K}_{\mathrm{s}} \quad$ saturation coeficient, \\ $\mathrm{V} \quad$ vial recipient mass,mg \\ BM biomass sample mass,mg}

\section{Greek symbols}

$\mu \quad$ growth rate, day ${ }^{-1}$

$\begin{array}{ll}\text { Subscripts } \\ \text { 0 } & \text { initial values } \\ \text { c } & \text { continuous mode } \\ \text { obs } & \text { observed } \\ \text { est } & \text { estimated }\end{array}$

\section{INTRODUCTION}

Recently, microalgae became prominent in the some economic areas, mainly due to its high nutritional value, production of biochemicals and potential for the production of biofuels. (Derner et al., 2006; Spolaore et al., 2006; Santos, 2016; Vargas et al., 2014; Mariano et al., 2010).The cultivation of microalgae requires specialized structures, called photobioreactors (PBR), able to guaranteeing good productivity and biomass quality. In the research and development of photobioreactors, the tendency is the development of automated systems of agitation, aeration, harvest and filtration, through the installation of sensors to evaluate biomass productivity (Filho, 2014; Havilik et al., 2013 Bacerra-celis et al., 2008). The most usual method is to collect small samples at certain time intervals and different techniques are done through more accurate methods and high performance analytical equipment such as liquid or gaseous chromatographs, biosensors, among others. However, some of these equipment may require high investments and also require periodic maintenance.

Production processes involving microorganisms usually require control to keep the operation at optimum, in order to increase productivity. The use of measurements of numerous process variables allows a strict control and monitoring of the process. Several techniques have been developed for online measurement of cell density and estimation of its concentration, most of them are based on turbidimetry and spectrophotometry, or through the electrochemical properties of the cultures as resistance and capacitance, measured by electrode inserted in the interior of the reactor (Salgado et al., 2001; Sandes, 2006, Mariano et al., 2009; Mello et al., 2009). This work aims at the low cost automation 
of photobioreactor by the construction of an optical density sensor to estimate the biomass concentration and a dilution system to operate it in continuous mode. This type of operation has some characteristics that make it possible to obtain uniform and constant biomass for a long period without the need for possible pauses in the process or to start a new crop and also the maintenance of optimum population density. For process automation, control and monitoring systems are required which, in addition to providing continuous microalgae production, will allow real-time data collection from experiments. This work also evaluated the biomass productivity of microalgae in photobioreactors operating in a continuous regime through the implementation of automation in photobioreactors in relation to manual conducted batch and semicontinuous mode.

\section{MATERIALS AND METHODS}

\section{Microalgae and growth conditions}

Microalgae used was Acutodesmus obliquus, maintained in $1.8 \mathrm{~L}$ flask with liquid medium $\mathrm{Chu}$, under the temperature of $20 \pm 2{ }^{\circ} \mathrm{C}$ and constant light for two $40 \mathrm{~W}$ fluorescent lamps. Agitation of the culture medium is done by the addition of compressed air $\left(1 \mathrm{~L} . \mathrm{min}^{-1}\right)$, also being the source of $\mathrm{CO}_{2}$ for cultivation.

\section{Dry biomass analysis}

The dry weight was determined through a gravimetric method and the results expressed in $\mathrm{g} . \mathrm{L}^{-1}$. From these measurements it was possible to determine the productivity of the culture. The determination of dry biomass was made once a day by filtration using a glass fiber filter paper with pore diameter of $47 \mathrm{~mm}$. The filter paper was kept in an oven at $60^{\circ} \mathrm{C}$ for 24 hours and then kept for 15 minutes in a desiccator with silica under vacuum, to remove additional moisture, and then weighted using an analytical balance. Filtration was carried out starting from a $5 \mathrm{~mL}$ sample from cultivation and filtered on the pre-weighted paper. The papers with biomass were kept in the same conditions described for the filter paper $\left(24 \mathrm{~h}\right.$ in oven at $60{ }^{\circ} \mathrm{C}$ and $15 \mathrm{~min}$ in desiccator) and weighted. The mass of the dried biomass is calculated as the difference between the mass of paper with biomass and paper without biomass.

\section{Fundamentals of continuous cultivation}

In cultures continuous system, fresh culture medium is added steadily while the cell culture is removed at the same rate of addition of the medium. This approach is based on the observation that the substrates are consumed from the culture medium while no cell multiplication and accumulation of biomass. Eventually, the culture stops growing in the absence of medium or limitation substrate or due to the presence of growth inhibitors. To maintain cell growth, the growth substrate must be replaced and inhibiting factors must be removed or diluted by addition of new medium (Lourenço, 2006; Richmond, 2004). As a practical manner, it is assumed that input rates of fresh medium in the system and culture pickup are equal and thus the cultivation volume remains constant. A peristaltic pump is most suitable for introducing fresh culture medium in the cultivation, since the mechanical parts of the pump do not contact with the medium. The culture can be removed by either peristaltic pump or by collecting overflow into an opening in the top of the bioreactor.

The bioreactor in continuous operation aims to keep growing in certain cell concentration (X) according to their optical density. The operating point is one whose specific growth rate of microalgae $(\mu)$ is maximum and is in the exponential phase of the growth curve. The cell concentration in the bioreactor is given by follow equation:

$$
\frac{d X}{d t}=\mu X-D X
$$

The concentration of nutrients (S) decreases proportionally cellular concentration $(\mathrm{X})$ in the reactor is given by the following equation:

$$
\frac{d S}{d t}=\left(S_{f}-S\right) X-\frac{\mu}{Y_{S / X}} X
$$

Where $Y_{s / x}$ is the substrate conversion factor in biomass and $\mathrm{S}_{\mathrm{f}}$ is the nutrient concentration of the feed and $\mathrm{D}=\mathrm{q} / \mathrm{V}$ is the reactor dilution rate, $\mathrm{q}$ is the flow rate of substrate addition and volume (V) of cultivation. The change in cell concentration is equal to the proportional growth less the withdrawal by dilution. In the steady state one has $\mathrm{dX} / \mathrm{dt}=0$, which implies $\mu=D$, this is, it is possible to change the growth rate by changing the dilution rate of the bioreactor. The Monod model demonstrates the influence of nutrient consumption by the cells on the specific growth rate and is given by:

$$
\mu=\mu_{\max } \frac{\mathrm{S}}{K_{s}+S}
$$

Where $\mu$ is the specific growth rate, $\mu \max$ specific rate of maximum growth, $\mathrm{S}$ the nutrient concentration, $\mathrm{K}_{\mathrm{s}}$ the constant saturation and it is equal to $\mathrm{S}$ when $\mu=0.5$. $\mu_{\max }$.

\section{Productivity of biomass}

The biomass productivity of batch and semi- 
continuous crops are calculated according to the following equation:

$$
P=\frac{X-X_{0}}{t-t_{0}}
$$

For continuous culture systems, the expression is given by the following equation:

$$
P_{c}=X \cdot D
$$

Where: $\mathrm{P}_{\mathrm{c}}$ is continuous biomass productivity $\left(\mathrm{g} . \mathrm{L}^{-1} \cdot \mathrm{day}^{-1}\right), \mathrm{X}$ is the biomass concentration $\left(\mathrm{g} . \mathrm{L}^{-1}\right)$ and $\mathrm{D}$ is the dilution $\left(\right.$ day $\left.^{-1}\right)$ of the PBR.

\section{Determination of total lipid content}

For the quantification of the total lipids of the cultures the methodology of cold extraction adapted by Housseini et al. (2015). This methodology allows the recovery of all apolar materials present in the sample (neutral lipids, pigments, phospholipids). The assays were performed in triplicate. $50 \mathrm{mg}$ of dry biomass microalgae sample ground in $14 \mathrm{ml}$ polypropylene falcon tubes were weighed. Then, 1.2 $\mathrm{mL}$ of the chloroform: methanol solution mixture (2: $1, \mathrm{v}$ : v) was added. The samples were then sonicated (Shuster Ultrasonic Washer, $40 \mathrm{kHz}$ frequency) for 30 minutes. After ultrasound, the samples were centrifuged (Daiki Centrifuge 80-2B) at $4000 \mathrm{rpm}$ for $15 \mathrm{~min}$; the supernatant with the lipid phase was recovered with a Pasteur pipette and reserved in another vial tube. This procedure is performed 3 times. After the third material withdrawal, the vial is taken to a gas exhaust chamber, where the solvents are evaporated. The lipid content in percentage was determined by the equation:

$$
\text { Total lipids }(\%)=\frac{V_{2}-V_{1}}{B M} \cdot 100 \%
$$

Where $V_{1}$ is the mass of the empty vial $(g), V_{2}$ is the mass of the vial with lipids $(\mathrm{g}), \mathrm{BM}$ is the dry biomass used in the extraction of lipids $(\mathrm{g})$.

\section{Sensor for biomass estimation}

A spectrophotometer cuvette, $10 \mathrm{~mm}$ optical path, has been adapted to act as a flow cell, by which the culture circulates to measure the variation of the light intensity through it.

Photosynthetic pigments such as chlorophyll, which gives the green color characteristic of most vegetables, absorb light very well in the bands of red and violet, reflecting the green light. Knowing that the scattering effect due to the reflection of the unabsorbed light generates an attenuation in the incident intensity in a similar way to the absorption, it is possible to define relation between variation of the amount of light that crosses a bucket and the concentration of microalgae biomass in the culture.

The sensor for determination of optical density consists of a $5 \mathrm{~mm}$ high light emitting diode (LED) and a phototransistor. A peak of emission of LED is observed at $517 \mathrm{~nm}$, measured with a spectrophotometer (Ocean Optics, model USB2000. The light emitted by the LED is captured on the opposite side of the cuvette by a phototransistor. The phototransistor is a device that works based on the photoelectric phenomenon. It can, at the same time, detect the incidence of light and provide a gain within a single component. In general, it has only two accessible terminals, the collector and the emitter, the base of the photosensitive region being exposed to incident light. Figure 1 shows the image of the optical density sensor constructed. A peristaltic pump performs the circulation of the culture through the cuvette, in a closed cycle, that is, the sample withdrawn from the PBR, flows through the cuvette and returns to the PBR intermittently. After its construction, it was covered with black opaque material in order to diminish the influence of the external luminosity.

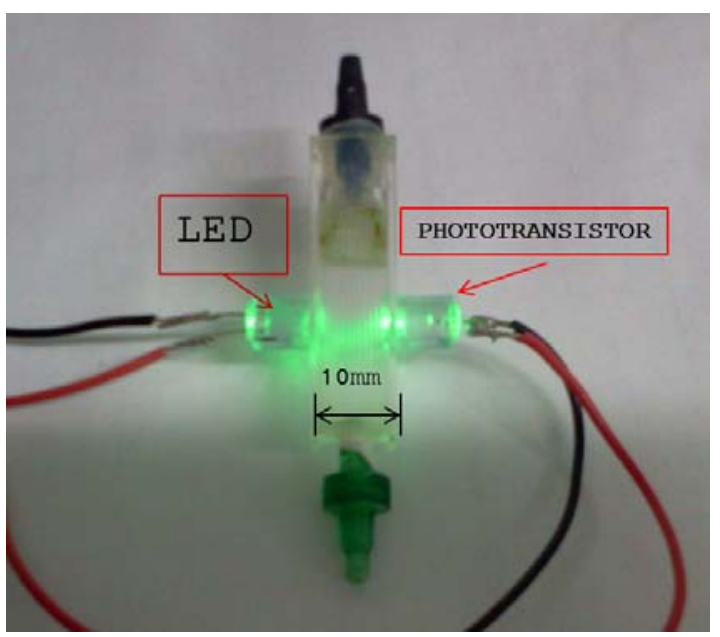

Figure 1. Optic density sensor for biomass estimation.

\section{Estimation's sensor error}

The error of estimation of the biomass value by the built sensor was evaluated from the mean absolute error (MAPE) in relation to the period when applied to the FBR dilution. This value indicates the accuracy that the sensor has in estimating the biomass concentration during the experiment and is calculated from the following equation:

$$
\operatorname{MAPE}(5)=\frac{100}{n} \sum\left(\frac{\left|X_{o b s}-X_{\text {est }}\right|}{X_{\text {est }}}\right)
$$




\section{Automated system for PBR control}

A automated culture system was developed to perform dilutions in the PBR according to the rates required with regularity in the additions and withdrawals of culture, besides guaranteeing an online and real-time monitoring of the FBR variables.

Figure 2 shows the P\&ID (pipe and instrumentation diagram) of the system (Figure 3 ). The signals of the concentration, temperature, iluminance and $\mathrm{pH}$ meter sensors are received by the microcontroller (Arduino MEGA 2560 ${ }^{\mathrm{TM}}$ ) through analog (concentration and $\mathrm{pH})$ and digital (temperature and iluminance) ports. These values are sent to the data server (Raspberry PI) through serial communication, by the USB connection between the two devices. A script was implemented for reading the serial port, recording the measurements in a database, and an XML file, used to arrange the data for the main page of supervision.

The supervisory system consists of three web pages: a main screen, which shows the values of the monitored variables, and has pump controls and experiment settings, a data insertion page obtained from the analyzes performed in the growth assessment as dry biomass, number of cells and absorbance.

\section{(1)Fluorescents lamps, (2) Peristaltics pumps, (3)} Microcontroler ( ATMega) e (4)Data server (Raspberry PI).

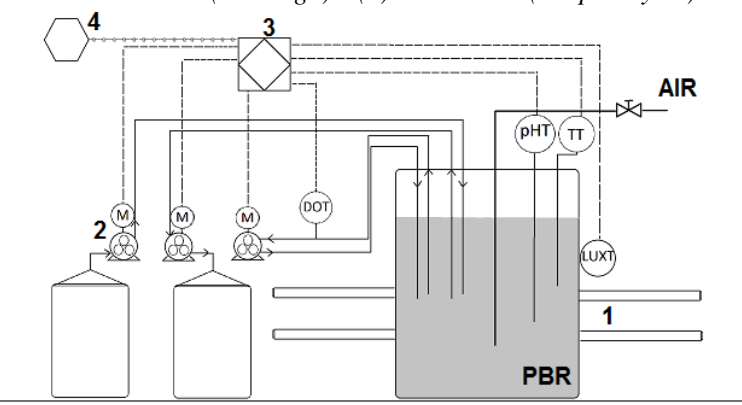

Figure 2. Process and instrumentation diagram.

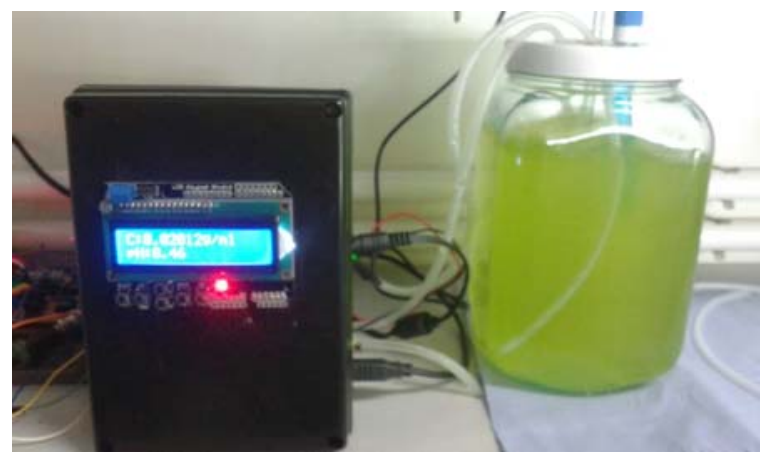

Figure 3. Automated Photobioreactor used in experiments.

The system also has a graph visualization page, which shows the time evolution of the variables monitored during the experiment.

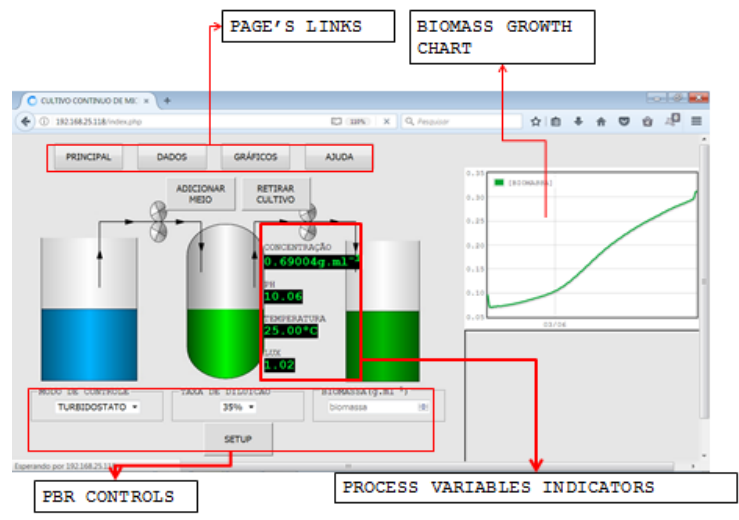

Figure 4.Web supervisiory for PBR.

\section{RESULTS AND DISCUSSION}

\section{Sensor calibration}

A sample of an advanced phase culture (biomass concentration $0.637 \pm 0.04$ g. $\mathrm{L}^{-1}$ ) was withdrawn from one of the Erlenmeyers kept in the NPDEAS culture room. Ten dilutions were prepared varying proportionately the cell concentration, from $100 \%$ sample to pure water. With a graduated pipette, microalgae culture with the proportion of distilled water was added, totalizing a total volume of $10 \mathrm{ml}$, as shown in Figure 5.

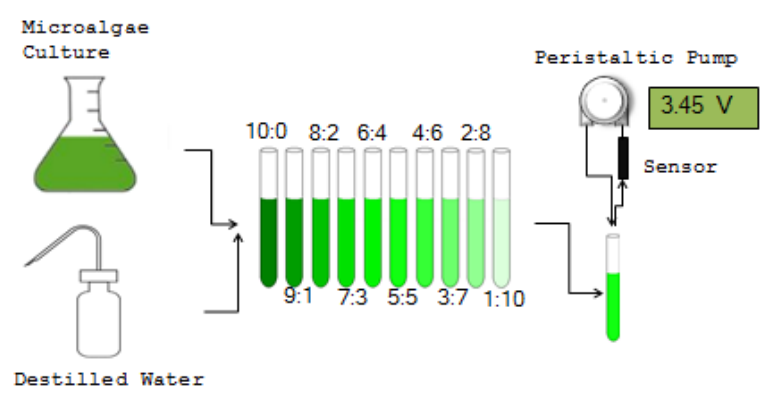

Figure 5.Calibration method.

The Figure 6 shows the calibration curve. The following correlation was obtained: $y=2.902 x$ with $\mathrm{R}^{2}=0.9939$. Where $\mathrm{y}$ is the absorbance and $\mathrm{x}$ the cellular concentration and $\mathrm{R}^{2}$ is the coefficient of determination. The attenuation of the luminosity with the increase of the concentration had an exponential decay. The measurement of the reference signal (water) was $3.45 \pm 0.6 \mathrm{~V}$.

\section{Batch and semicontinuous cultivation}

Cultures were carried out in the batch and semicontinuous regimes conducted manually. The growth model (Eq. (1), (2) and (3)) was adjusted to the experimental biomass data of the batch culture, by minimizing the sum of the quadratic error. 


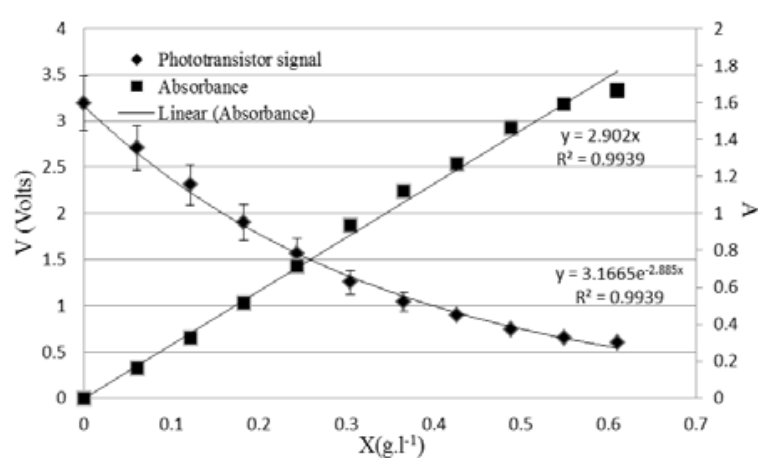

Figure 6. Calibration curve of sensor.

The differential equations were solved using the Euler method and the parameters were estimated using the Solver tool (Microsoft Excel ${ }^{\mathrm{TM}}$ ). The estimated parameters were the maximum growth rate $\left(\mu_{\max }=0.48\right.$ day $\left.^{-1}\right)$, the saturation coefficient $(\mathrm{Ks}=$ $0.2148)$ and the conversion factor $\left(Y_{x / s}=0.3146\right.$ day $\left.^{-1}\right)$.

The maximum biomass concentration achieved in batch cultivation (Figure 7) was 0.987 g.L.-1 According to the model, the biomass concentration will grow to a certain extent, reaching a period of deceleration and reaching a stationary phase, caused by the decrease of nutrient availability. However, the semi-continuous regime does not present this profile, since periodic dilutions are carried out, maintaining the culture in conditions to maintain an exponential growth for a long period of time (Santos, 2016). The average productivity for the growing period was $49.97 \mathrm{mg} . \mathrm{L}^{-1} \cdot \mathrm{dia}^{-1}$.

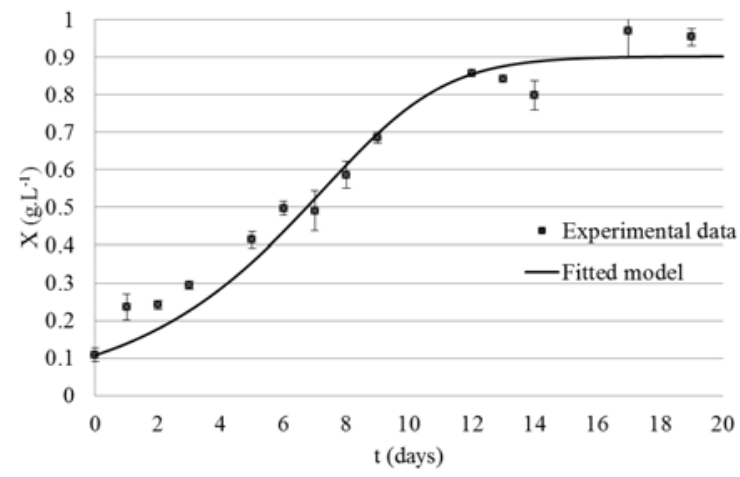

Figure 7. Batch growth curve.

The semicontinuous crop grew in batch until the $7^{\text {th }}$ day. The dilutions were $40 \%$, performed at the time the culture reached 0.7 g. $\mathrm{L}^{-1}$ and the culture remained in that regime until the $19^{\text {th }}$ day (Figure 8 ). Renewal of the culture medium creates an environment conducive to high biomass yields, since the addition of nutrients favors cell growth, while the removal of part of the culture guarantees a culture with small concentrations of metabolites and prevents self-shading. An adaptation phase was observed shortly after dilutions. The average productivity for the growing period was $58.11 \mathrm{mg}$. $\mathrm{L}^{-}$ ${ }^{1} \cdot \mathrm{dia}^{-1}$.

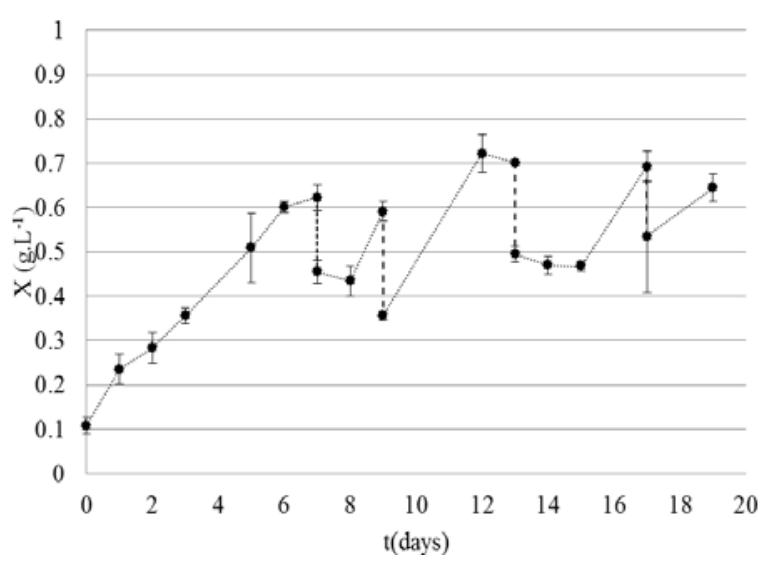

Figure 8. Semicontinuous growth curve.

\section{Continuous cultivation}

A culture was started and maintained in a conventional growth regime (without dilution) for 6 days reaching the mean cell number of $608 \pm 28.104$ and biomass concentration of $0.686 \pm 0.008 \mathrm{~g} . \mathrm{L}^{-1}$. From the 6th day, the FBR dilution with the developed dilution system was started. The FBR was initially applied at a rate of $0.05 \mathrm{day}^{-1}$. This initial dilution value was used to avoid large losses of biomass at first, already observed in preliminary experiments.

The rate was changed on the 11th day to 0.2 day $^{-1}$. This value is based on previous batch and semicontinuous growth rates. The chemostat maintains the availability of nutrients for maintenance of the cells. By changing the dilution rate, you can change the growth rate. After determining the pump flow rates, the culture medium feed rates and biomass withdrawal were calculated according to the stipulated dilution rates. The dilution system worked correctly, the volumes of the aliquots collected through the pumps remained throughout the experiment, thus conferring regularity on FBR dilution. Two reservoirs were used, one to store the fresh culture medium to be added to the reactor while the other is used in the collection. Figure 34 shows the evolution of the biomass concentration in the continuous regime and the biomass graph estimated by the developed sensor.

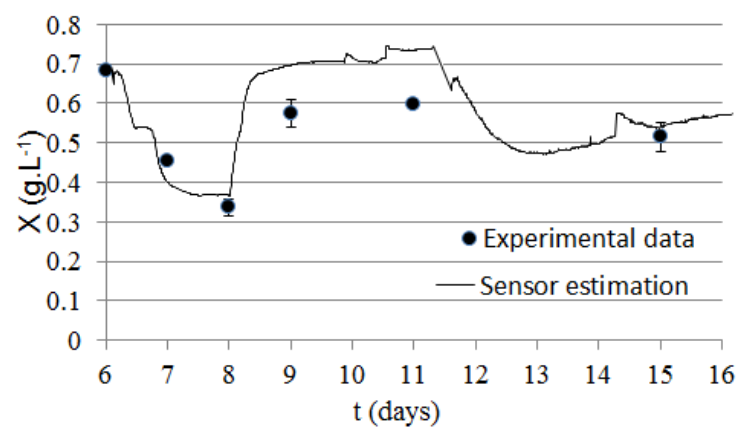

Figure 9. Continuous growth curve. 
The average sampling rate was 5 minutes. During the first two days, there was a sudden drop in the biomass concentration. This phenomenon can be attributed to the change in cultivation regime, which caused a sudden precipitation by the advanced cell population. As the only PBR's means of agitation, the injected air flow rate was increased to the maximum value allowed by the air pipe, in order to homogenize the culture in order that the sensor reading was consistent with the actual concentration inside the FBR. From this moment a significant increase in biomass concentration was observed and this change was observed instantaneously from the reading of the sensor, demonstrating that it is able to perceive sudden changes. The mean error of the biomass estimation by the sensor during the dilution period was $8.46 \%$ (Table 1 ). The average productivity for the growing period was $74.6 \mathrm{mg} \cdot \mathrm{L}^{-1} \cdot \mathrm{dia}^{-1}$.

Table 1. MAPE calculation.

\begin{tabular}{|c|c|c|}
\hline $\begin{array}{c}\text { Biomass } \\
\text { (analyis) } \\
\mathbf{X}_{\text {obs }}\left(\text { g. } L^{-1}\right) \\
\end{array}$ & $\begin{array}{c}\text { Biomass } \\
\text { (estimated) } \\
\text { X }_{\text {est }}\left(\text { g.L } \mathbf{L}^{-1}\right)\end{array}$ & $\begin{array}{c}\text { Percentual } \\
\text { error } \\
(\%) \\
\end{array}$ \\
\hline 0.686 & 0.684 & 0.292 \\
\hline 0.532 & 0.455 & 16.816 \\
\hline 0.364 & 0.337 & 8.104 \\
\hline 0.651 & 0.578 & 12.653 \\
\hline 0.638 & 0.598 & 6.680 \\
\hline \multirow[t]{2}{*}{0.483} & 0.515 & 6.206 \\
\hline & APE (\%) & 8.46 \\
\hline
\end{tabular}

\section{Lipids productivity}

The Figure 10 shows the comparison of the biomass and lipid productivities observed in the experiments of this work. For the batch regime, the lipid content (17.88\%) was quantified in the last day of cultivation, already in the stationary phase, characterized by the lack of nutrients consumed during growth. Due to the limitation of nitrogen, the main nutrient that participates in cell multiplication, the metabolism of microalgae alters and begins to accumulate energy in the form of lipids. For the semi continuous regimen, the extracted aliquots were extracted at the time of dilution, in order to obtain an average of $17.91 \%$. In this regime mode, the biomass grows up to a certain point until the moment of dilution, during this period there is also a small accumulation of lipids, since some of the cells are in advanced age. In the continuous regime the sample used for the extraction was in the period where the FBR was operating with the dilution rate of 0.2 day $^{-1}$, and the lipid content obtained was $11.47 \%$. The constant dilution of the reactor implies that there will be no limitation by nutrients, thus favoring the multiplication of cells instead of the production of lipids. In addition, it has been observed that even increasing the limitation of nitrogen in the continuous regime, it was found that starch acts as the primary storage in the species Acutodesmus obliquus, and the lipids only accumulate when the starch synthesis rate is limited (Remmers et al., 2017). It may be considered as an additional strategy is the multi-stage cultivation i.e. the use of continuous cultivation in a first step, providing high biomass yield for a phase of accumulation of lipid material, it may be a heterotrophic crop, for example where there is addition of inorganic carbon.

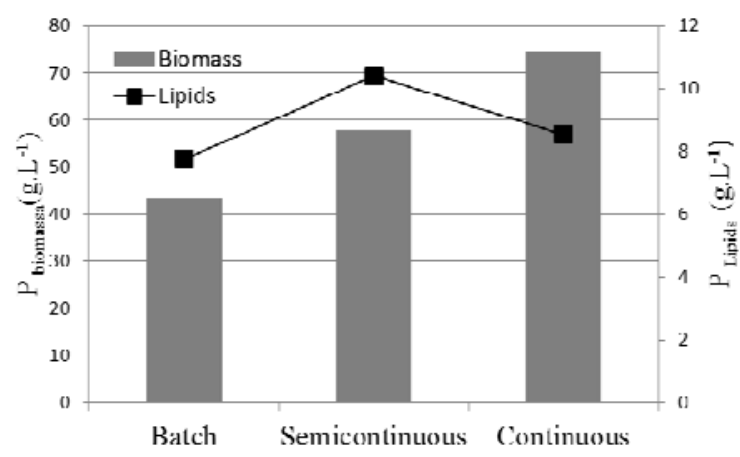

Figure 10. Biomass and Lipids productivity.

\section{CONCLUSIONS}

Monitoring the biomass concentration is an important variable in the characterization of photobioreactor operation. The developed sensor presented a concordant response with the variation of biomass inside the photobioreator, but the calibration should be done in bands of concentrations close to the operating range. The dilution system showed a stable operation with constant addition and withdrawal volumes throughout the experiment. The proposed system can be used in different types of bioreactors

\section{ACKNOWLEDGEMENTS}

We thank the PIPE, CNPq, the CAPES and the NPDEAS team whose support was essential to this research.

\section{REFERENCES}

Becerra-Celis, G., Tebbani, S., Joannis-Cassan, C., Isambert, A., and Siguerdidjane, H., 2008, Control Strategy for Continuous Microalgae Cultivation Process in a Photobioreactor, in: 17th IEEE International Conference on Control Application, pp.684-689.

Derner, R. B.,Ohse, S., Villela, M., Carvalho, S. M., and Fett, R., 2006, Microalgas, Produtos e Aplicações, Ciencia Rural, Vol. 6, pp. 1959 -1967. (in Portuguese)

Lourenço, S. O., 2006, Cultivo de Microalgas Marinhas - Princípios e Aplicações, São Carlos, RiMa. (in Portuguese)

Mariano, A. B., Torrens, J. C. L., Satyanarayana, K. G., and Vargas, J. V. C., 2010, 
Energia Autossustentável a Partir de Biodiesel Derivado de Microalgas, in: $4^{\circ}$ Congresso Internacional de Bioenergia, Fundação de Pesquisas Florestais do Paraná, Paraná, Curitiba. (in Portuguese)

Mariano, A. B., Vargas, J. V. C., and Melo, T. C., 2009, Uso de Sensores de Infravermelho no Controle do Cultivo de Microalgas em Fotobiorreatores Compactos para Produção de Biomassa e Biodiesel, in: $3^{\circ}$ Congresso da Rede Brasileira de Tecnologia de Biodiesel, Ministério da Ciência e Tecnologia, Brasilia. (in Portuguese)

Mello, T. C., Vargas, J. V. C., and Mariano, A. B., 2009, Density Control of Microalgal Cultures using Infrared Sensors, in: 20th International Congress of Mechanical Engineering, COBEM, Rio Grande do Sul, Gramado.

Richmond, A., 2004, Handbook of Microalgal Culture: Biotechnology and Applied Phycology, Oxford Blackwell Science Ltda.

Remmers, I. M., Hidalgo-Ulloa, A., Brandt, B. P., Evers , W. A. C., Wijffels, R. H., and Lamers, P. P., 2017, Continuous Versus Batch Production of Lipids in the Microalgae Acutodesmus obliquus, Bioresources Technology, Vol. 244, pp. 1384-1392.

Sandnes, J. M., Ringstad, T., Wenner, D., Heyerdahl, P. H., Källqvist, T., and Gislerød, H. R., 2006, Real-Time Monitoring and Automatic Density Control of Large-Scale Microalgal Cultures using Near Infrared (NIR) Optical Density Sensors, Journal of Biotechnology, Vol. 122, No. 2, pp.209-215.

Spolaore, P., Joannis-Cassen, C., Duran, E., and Isambert, A., 2006, Comercial Applications of Microalgae: Review. Journal of Bioscience and Bioengineering, Vol. 101, No. 2, pp. 87-96.

Santos, B., 2016, Estratégias para Aumentar a Produtividade de Biomassa de Microalgas com Carbono Orgânico, Master Thesis, PIPE-UFPR, Curitiba, PR. (in Portuguese)

Vargas, J. V. C., Mariano, A. B., Corrêa, D. O., and Ordonez, J. C, 2014, The Microalgae Derived Hydrogen Process in Compact Photobioreactors, International Journal of Hydrogen Energy, Vol. 39, pp. 9588-9598. 